\title{
The Administrator's Perspective
}

\section{Addis Tamire Woldemariam}

Office of Minister, Ministry of Health, Federal Democratic Republic of Ethiopia

addishoneyt@gmail.com

First of all, I would like to congratulate all involved in producing this timely and thorough report on Making Fair Choices on the Path to Universal Health Care (WHO, 2014). I offer my response under three headings:
a) Overall comments from the viewpoint of an administrator in a low-income country.
b) Issues connected with extending services, access and financial protection.
C) Concluding reflections.

\section{Overall Comments}

The report is important because it comes at a time when there is a lot of confusion about universal health care (UHC). UHC is a 'buzz-word'. Yet, the concept often appears crude and abstract. The report tries to unpack the concept, fleshing out what it means as well as flushing out what it does not mean. In particular, for someone involved in day-to-day policy-making and administration in Ethiopia, the report is timely and relevant for two reasons.

Firstly, Ethiopia kicked off the journey to UHC over a decade ago with the introduction of the Health Extension Program (HEP) in 2003, a home grown, innovative, community-based strategy to deliver disease prevention, health promotion and selected high impact curative interventions at community level. The HEP has resulted in active community participation in the creation of awareness, behavioral change, and community organization and mobilization. It has also significantly improved the utilization of health services by bridging the gap between the community and health facilities through health extension workers (Assessment of the Performance of HEWs, Ministry of Health, 2006). Through the HEP, rural communities have been able to access essential health services provided at village and household levels. The HEP has also served as a vehicle for bringing key maternal, neonatal and child health interventions to the 
community. The report helps us see where we have succeeded, the mistakes we have made and where we have failed. It also suggests what we need to do next to achieve UHC.

Secondly, Ethiopia has embarked on developing a 20-year Health Sector Plan as it aspires to make the transition from a low-income to a middle-income country in the next decade. The report is an important input for that exercise, offering criteria for the assessment of our future performance and a sense of priorities.

In this context, whilst recognizing continuing scope for debate, the report ventures to suggest, in specific terms, how to make fair choices on the path to UHC. The word 'fair' sounds easy when written. However, it is very complicated to interpret and difficult to implement in practice. Indeed, some may even pose the challenge of whether it is 'wise' to make 'fair choices'. According to the report, to achieve UHC countries must expand priority services, include more people in the scope of service and reduce out-of-pocket payments. However, the question of fairness and equity come into play when it is time to decide what to expand first, whom to include first, and how to shift from out-of-pocket payment toward pre-payment. That is why, in addition to making 'fair' choices, we have to also make 'wise' choices depending on specific contexts and the trade-offs they bring. Such contexts may require expanding coverage for low- or mediumpriority services before there is near-universal coverage for high-priority services. Wisdom here means striking a reasonable balance between vertical and horizontal equity, illustrated by expanding prevention and treatment for non-communicable diseases and injury before near universal coverage for communicable diseases. Communicable diseases will continue to receive attention but non-communicable diseases are now ceasing to be low- to medium-priority and becoming high priority as their burden increases over time.

\section{Extending Services, Access and Financial Protection}

I concur with the report's endorsement, particularly in Chapter 1, of UHC as a major goal, a leadership priority and a central theme in the post 2015 development agenda. It is important to reiterate the assertion that UHC is the 'single most powerful concept public health has to offer'. However, what does this mean in practice? Here, Ethiopia's experience is relevant. On the path to UHC Ethiopia has done a lot to improve access to essential services and to deal with matters of financial risk protection. 
The key to Ethiopia's approach has been its flagship Health Extension Program. The HEP has four health sub-programmes: Disease Prevention and Control, Family Health, Hygiene and Environmental Sanitation and, finally, Health Education and Communication. This approach is basically in line with the Alma-Ata Declaration. These sub-programmes are split into sixteen health extension packages covering health promotion, disease prevention, and selected high impact curative health services delivered by more than 38,000 thousand government salaried health extension workers (HEWs). Every village with 5000 residents builds a health post. Two female HEWs who have completed tenth grade education are recruited from the same community and trained in HEP modules for one year, after which they return home as salaried frontline health care staff. The HEP is linked well with the network of primary health centers and hospitals ensuring the continuum of care for the population.

The key steps necessary in the development of the HEP can be summarized as follows:

- Developing a focus on high priority health services like HEP packages;

- Developing a focus on innovative ways to deliver these essential services, most notably by using less highly trained health care personnel like the HEWs.

- Shifting some of the tasks conventionally carried out by high level health professionals to a less highly trained health workforce. For instance, single-rod contraception insertion and removal is carried out by HEWs, whilst emergency obstetric and surgical procedures are undertaken by Integrated Emergency Surgical Officers.

- Encouraging unprecedented voluntary community participation through the new approach called the Health Development Army (HDA). The HDA is a network of women volunteers organized to promote health, and prevent disease through community participation and empowerment. The HDA has effectively facilitated the identification of local salient bottlenecks that hinder families from utilizing key Maternal, Neonatal and Child Health (MCH) services and to come up with locally grown and acceptable strategies for addressing ongoing issues. To date, we have been able to mobilize over three-million women to be part of an organized HDA.

The general lesson from this example is that good policy on the path to UHC depends on the way that services are reorganized and developed rather than on the choices - whether 'fair' or not that are made about services that are regarded as fixed from the point of view of their organization. It is the way the services are reorganized and developed that matters on the path to 
UHC, not necessarily making 'fair choices. This is so because there is an issue of 'fair in whose eyes?', be it policy-makers, beneficiaries or the people at large.

Alongside the development of these services, the aim has also been to ensure financial risk protection. To this end, we have put in place the following:

- A fee waiver for critical maternal and child health services.

- A fee exemption for the poorest of the poor.

- Affordable and relatively high quality health care service provision by the government. The fifth round Household Health Service Utilization Survey revealed that the Government is the major health care provider. These services are accessed by the majority (Ethiopia's Household Health Services Utilization and Expenditure Survey: Briefing Notes, Ministry of Health, 2014).

- These measures have been complemented by the development of insurance schemes:

- Social Health Insurance is a compulsory scheme designed for people in the formal sector. Employees contribute 3\% of their salaries and their employers do the same.

- Community Based Health Insurance is a voluntary scheme for those in the informal sector. Here, people contribute a flat rate payment, unrelated to the ability to pay, the government at different levels subsidizes services and the poorest are exempt from any obligation to pay. The lack of valid, reliable, timely and useful information on the level of income from the informal sector makes it nearly impossible to gauge the fee level for each individual. So, until reliable data can be collected, the charging of a flat rate was the selected as the best choice, as a temporary measure.

The development of the HEP packages has therefore expanded priority services and included more people, (whether urban, agrarian or pastoral), although performance varies across these groups. However, the reduction of out of pocket payments is still a daunting challenge. Although the shift from out of pocket payment towards pre-payment is being tried, a huge task still lies ahead. Health insurance (progressive prepayment with pooling of funds) is an upcoming challenge to the system. Issues of fairness and equity remain, of course, despite the policy efforts made. There are still huge disparities between: the rich and the poor; men and women; urban and rural; the regions; and the able and the disabled. It is virtually impossible to provide tertiary specialty care. 


\section{Public Accountability and Participation}

Public participation has been important in the attempt to build up services in Ethiopia. The following have been the principal measures:

1) The aforementioned Health Development Army, with now more than three million volunteers across Ethiopia has been recruited at the community level.

2) The governance structures of health centers and hospitals invite community representation. The community representatives, in the form of the Health Development Army, are members of their governing boards. These organized community groups are represented by individuals selected by the community during their regular meetings. It is not a token representation but one that empowers and ensures representatives are active in planning, execution, implementation and evaluation of performance.

3) Public fora are sessions every quarter involving interactions and dialogue with the community. Every service providing institution has identified its participants for these fora. A joint plan is prepared and monitored and evaluated by the fora. In Ethiopia, besides being recipients of services, the communities are engaged in shaping the system and how services are financed and delivered.

The basic principle behind these developments is that members of the community are not simply recipients of services; they are also engaged in shaping the system and how services are financed and declared. The 20-year forward-look envisions community participation, empowerment and ownership as one of the seven pillars of the Ethiopian health sector. This experience underlines the importance of public participation as discussed in the report (Chapter 7).

\section{Conclusions}

The report is open to challenge on not dealing with the different ways in which 'equity' might be defined. Equity may either take a horizontal or a vertical form. On the one hand horizontal equity means providing the same quality services to people with the same problems wherever they are (say urban or rural). On the other hand, vertical equity means providing necessary care according to the level of need, e.g. offering cardiac surgery to one who suffers an operable heart condition, which may be relatively expensive, or providing simple Chloroquine, which is relatively cheap, to someone suffering Malaria. The report seems to 
give priority to horizontal over vertical equity. If this is so, how is it possible to say that the choice is 'fair' in an unambiguous sense? This is the dilemma of respecting individual rights to health care, but it raises the problem as to how far the principles of the report can be practical policy principles.

There is also the question of whether choice is to be made at the level of the community or the level of the individual. There is a distinction between an intervention being cost-effective at the level of the individual and an intervention that has high impact as measured by the positive gain as a result of the intervention, when that gain is added up over a number of individuals. So, in addition to the principles of costeffectiveness, priority to the worst off and financial risk protection, which are advanced in the report (p.29), an additional criterion of service selection should be high total rate of return.

There is also another trade-off not referred to in the report. Fair expansion of coverage is said to mean giving priority to the worse off. However, if all people are enrolled into a pre-payment scheme with a pooling of funds (as in a social insurance scheme), they should be equally entitled to the benefits according to their needs, without regard to whether they can pay or not, especially if their contribution based on the ability to pay. So is it a matter of prioritizing the worse off over the well-off or ensuring that the worse off are not left behind?

In the report the words 'careful' or 'carefully are frequently used in the context of 'making choices'. Making careful choices is good but by itself it does not ensure fairness or equity. Perhaps, if no choice is completely 'fair', we should simply talk about 'tough' or 'hard' choices. 'Wise' or 'prudent' choices are necessary among choices that are reasonable (compare Rumbold and Wilson, 2014). Reconciling costeffectiveness and efficiency with equity may be impossible, making identification of 'acceptable' trade-offs very difficult if not absolutely impossible. 


\section{References}

Ministry of Health (2006) Assessment of the Performance of HEWs.

Rumbold, B. and Wilson, J. (2014) 'Reasonable Disagreement and the Generally Unacceptable'. This issue.

World Health Organisation (2014), Making fair choices on the path to universal health coverage. Geneva:

World Health Organisation. Available at

http://apps.who.int/iris/bitstream/10665/112671/1/9789241507158 eng.pdf?ua=1 - last accessed 27/07/14. 